\title{
WestVirginiaUniversity
}

THE RESEARCH REPOSITORY @ WVU

Graduate Theses, Dissertations, and Problem Reports

2004

\section{Specific aspects of social anxiety related to children's peer sociometric status}

Abby H. Friedman

West Virginia University

Follow this and additional works at: https://researchrepository.wvu.edu/etd

\section{Recommended Citation}

Friedman, Abby H., "Specific aspects of social anxiety related to children's peer sociometric status" (2004). Graduate Theses, Dissertations, and Problem Reports. 2034.

https://researchrepository.wvu.edu/etd/2034

This Thesis is protected by copyright and/or related rights. It has been brought to you by the The Research Repository @ WVU with permission from the rights-holder(s). You are free to use this Thesis in any way that is permitted by the copyright and related rights legislation that applies to your use. For other uses you must obtain permission from the rights-holder(s) directly, unless additional rights are indicated by a Creative Commons license in the record and/ or on the work itself. This Thesis has been accepted for inclusion in WVU Graduate Theses, Dissertations, and Problem Reports collection by an authorized administrator of The Research Repository @ WVU. For more information, please contact researchrepository@mail.wvu.edu. 
Specific Aspects of Social Anxiety Related to Children’s Peer Sociometric Status

Abby H. Friedman

\begin{abstract}
Thesis submitted to the Eberly College of Arts and Sciences

at West Virginia University

in partial fulfillment of the requirements

for the degree of
\end{abstract}

\author{
Master of Science \\ in \\ Psychology
}

\author{
Tracy L. Morris, Ph.D., Chair \\ Cynthia M. Anderson, Ph.D. \\ Jennifer A. Margrett, Ph.D. \\ Department of Psychology \\ Morgantown, West Virginia \\ 2004
}

Keywords: peer sociometrics, social anxiety, SASC-R, SPAI-C

Copyright 2004 Abby H. Friedman 


\begin{abstract}
Specific Aspects of Social Anxiety Related to Children’s Peer Sociometric Status Abby H. Friedman, B.A.
\end{abstract}

The present study examined the association between specific aspects of social anxiety and sociometric status. Participants included 268 children in grades 4, 5, and 6. The children completed the Social Anxiety Scale for Children - Revised (SASC-R) and the Social Phobia and Anxiety Inventory for Children (SPAI-C). A sociometric nomination procedure was used to categorize participants into sociometric status groups (i.e., neglected, rejected, controversial, popular, and average). Results replicated and extended previous literature. Neglected children scored the highest on both measures of social anxiety, followed by rejected children. This was one of the first investigations to associate socometric status with SPAI-C factor scores, with neglected children scoring the highest on Cognitive and Physiological Symptoms, Avoidance, and Public Performance factors. Based on these findings, implications for social anxiety prevention and intervention are discussed. 


\section{Acknowledgments}

I would like to express my sincere gratitude to Dr. Tracy Morris, my advisor and committee chair. Her support, time, and effort devoted to this thesis and my academic career, are greatly appreciated. I would also like to thank the other members of my thesis committee, Dr. Cynthia Anderson and Dr. Jennifer Margrett, for their feedback, support, and contributions to this project. I would also like to acknowledge and thank my colleague and best friend, Lisa Greene, for her sense of humor, warmth, and support throughout this project. Finally, I would like to express great appreciation to my parents, Margaret and Steve Friedman, whose unconditional love and support are amazing and have provided the foundation for every accomplishment in my life. 


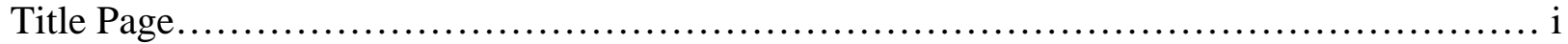

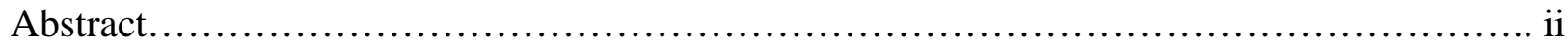

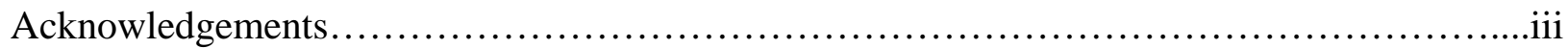

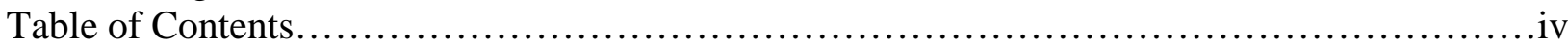

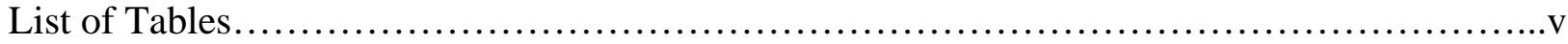

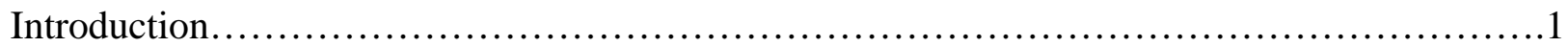

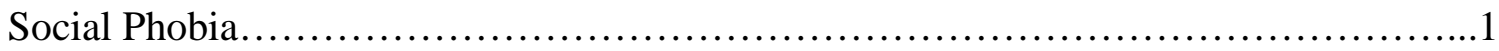

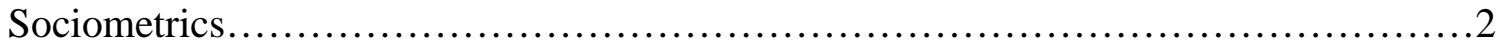

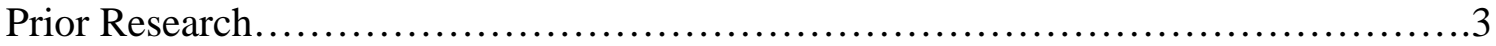

Discrepancies Between Prior Studies...................................................5

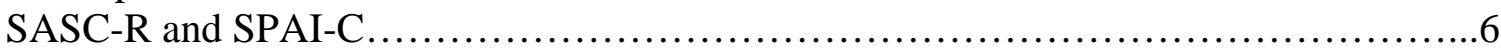

Comparison of the SPAI-C and SASC-R............................................

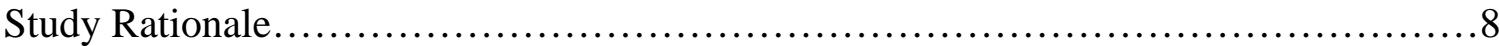

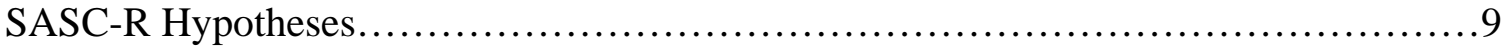

SPAI-C Hypotheses.....................................................................

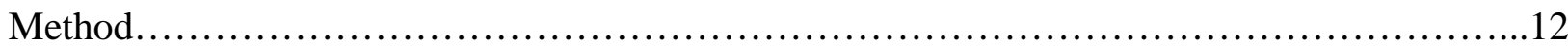

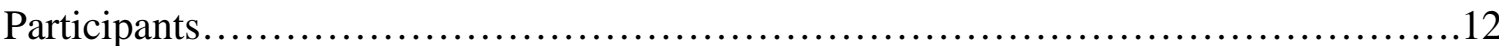

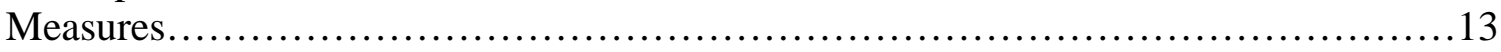

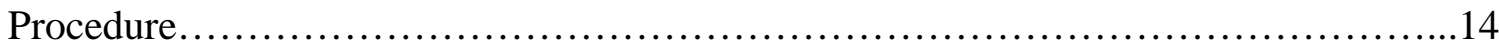

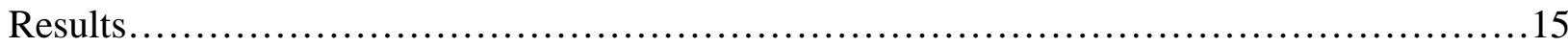

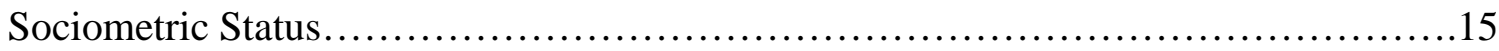

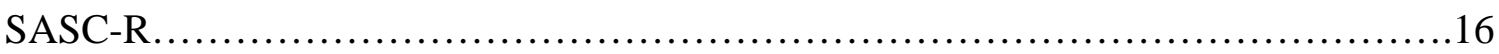

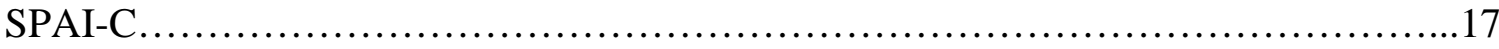

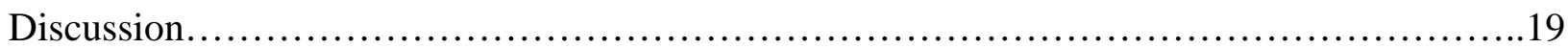

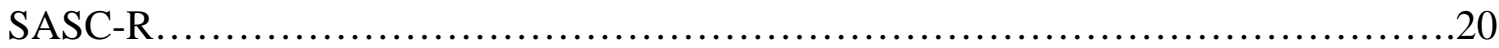

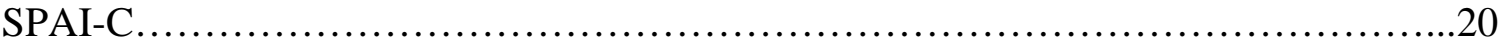

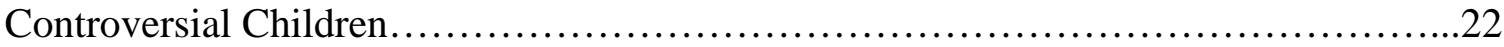

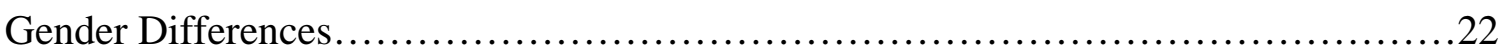

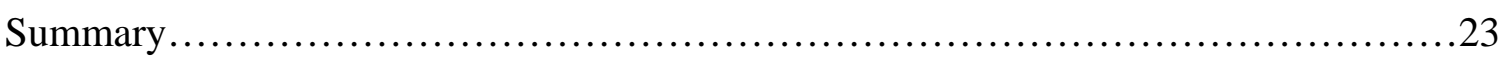

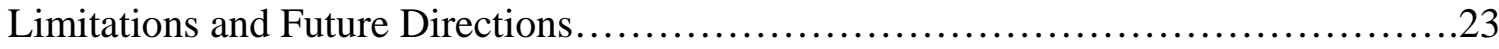

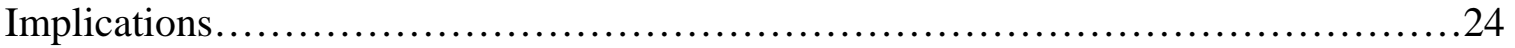

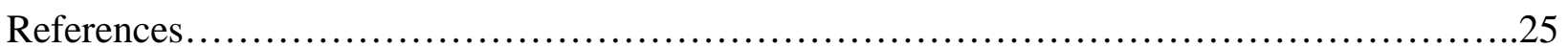




\section{List of Tables}

Table 3. Mean SASC-R Scores by Sociometric Status Groups................................35

Table 4. Pairwise Comparisons by Gender for the SPAI-C...................................36

Table 5. Mean SPAI-C Scores by Sociometric Status Groups.................................

Table 6. Summary of Findings............................................................ 
Specific Aspects of Social Anxiety Related to Children’s Peer Sociometric Status

Low quality friendships and poor peer relationships among children have been linked to the development and maintenance of mental health, school, and social problems (Berndt, 2002; Woodward \& Fergusson, 1999; Ladd \& Troop-Gordon, 2003). Peer relationship difficulties have been associated with various types of psychopathology (e.g., conduct disorder, attention deficit hyperactivity disorder, social phobia, depression; Woodward \& Fergusson, 1999; Harrist, Zaia, Bates, Dodge, \& Petit, 1997). Specifically, research has shown children with social anxiety to have a higher risk of developing problematic social relationships than non-socially anxious children (Ginsburg, La Greca, \& Silverman, 1998; Strauss, Lahey, Frick, Frame, \& Hynd, 1988).

Social anxiety disorder, also called social phobia, is exemplified by unrelenting feelings of nervousness and fears of embarrassment and humiliation in social and performance situations. Social anxiety disorder is differentiated from other anxiety disorders because it is restricted to social situations in which one fears being scrutinized (American Psychiatric Association [APA], 2000). Social phobia is one of the most common psychiatric disorders (Kashdan \& Herbert, 2001; Kessler, McGonagle, Zhao, Nelson, Hughes, Eshelman, et al., 1994), affecting approximately 7 to $13 \%$ of individuals at some point in their lives (see Furmark, 2002, for a review). The age of onset for social phobia is early in comparison to other psychological disorders, usually beginning between the ages of 8 and 18 (see Kashdan \& Herbert, 2001, for a review; Otto, Pollack, Maki, Gould, Worthington, Smoller, et al., 2001). Social fears are highly prevalent in both community and clinical samples of children (Epkins, 2002). The most common feared situations for socially anxious children occur in the school setting and include overt public behaviors (e.g., speaking in public, eating in public) and unstructured social interactions (Beidel \& Turner, 1998; Beidel \& Morris, 1995). Social anxiety may prevent children from participating 
in peer-interactive activities that are a crucial part of typical development (La Greca \& Stone, 1993).

\section{Sociometrics}

A procedure known as sociometric nominations, in which children identify three peers they like to play with the most and three they like to play with the least, has been used to categorize children based on their social status (Coie, Dodge, \& Coppotelli, 1982). Sociometrics have been used to study the development of psychopathology, target children for intervention and prevention programs, and evaluate the social validity of such programs (Ladd, 1999; Ladd, Buhs, \& Troop, 2002; Morris, Messer, \& Gross, 1995; French \& Waas, 1985). Sociometric procedures also have been used to effectively predict the later development of behavioral disturbances and psychosocial problems in children (Ladd \& Troop-Gordon, 2003; Bierman \& Wargo, 1995), and have concurrent validity with other measures of social status, including behavioral observations (Rosenblum \& Olson, 1997).

Sociometric nomination procedures have been applied in clinical (Ginsburg et al., 1998) and naturalistic settings (Ladd et al., 2002), and with a variety of age groups, including preschoolers (Musun-Miller, 1990), elementary school children (La Greca et al., 1988), and adolescents (Inderbitzen et al, 1997). Sociometric nomination procedures have the advantage of being used with children as young as 3-years-old, whereas self-report methods of assessment are limited to use with children who are able to read at a third grade or higher level (see Prout \& Chizik, 1988, for a review).

Sociometric status groups include popular, neglected, rejected, controversial, and average children (Coie et al., 1982). Popular children are favored by their peers, receiving a high proportion of liked most nominations and a low proportion of liked least nominations, rejected 
children receive a high proportion of liked least nominations and a low proportion of liked most nominations, and neglected children are neither liked nor actively disliked and are relatively ignored. Controversial children receive a high proportion of both liked most and liked least nominations, while average children receive a moderate proportion of liked most and liked least nominations.

Social Anxiety and Sociometric Status

Studies examining the association of social anxiety and peer sociometric status have produced varying results. La Greca, Dandes, Wick, Shaw, and Stone, (1988) evaluated the association between social status groups and levels of anxiety in 287 second through sixth graders. The Social Anxiety Scale for Children (SASC), the Revised Children’s Manifest Anxiety Scale (RCMAS; Reynolds \& Richmond, 1978), and two sociometric measures were used to measure social and general anxiety (respectively) in relation to peer social status. The SASC was a newly developed measure used to assess social anxiety in children and its initial psychometric properties also were investigated in this study. The two sociometric measures included a positive nomination procedure in which children indicated the three peers they liked to play with the most and a rating procedure using a 5-point scale to demonstrate how much they liked to play with each of their classmates. Results demonstrated that neglected children reported higher levels of general and social anxiety than the other social status groups and also scored highest in the area of social avoidance. Rejected children reported experiencing lower levels of social anxiety than neglected children, but higher levels than their controversial, average, and popular peers.

In a subsequent study on the psychometric properties of the revised version of the SASC (SASC-R), La Greca and Stone (1993) assessed levels of social anxiety and self perception as 
related to sociometric classification. Consistent with La Greca et al. (1988), the results showed higher overall levels of social anxiety for neglected children compared to other sociometric groups. In addition, neglected and rejected children did not score significantly different from one another on the FNE subscale of the SASC-R. Neglected children scored higher than the other sociometric status groups in the areas of social avoidance and distress in new and general situations, with new and unfamiliar peers.

Inderbitzen, Walters, and Bukowski (1997) assessed social anxiety as associated with sociometric status in a study similar to the La Greca et al (1988), and La Greca and Stone (1993) studies, using 973 adolescents in grades sixth through ninth. The Social Anxiety Scale for Adolescents (SAS-A; La Greca \& Lopez, 1998) was used as a measure of the adolescent’s anxiety in social situations. A sociometric nomination procedure was used in which adolescents selected three peers that matched specific descriptors (e.g., like most, like least, best leader, fights the most). The results were comparable to La Greca et al. (1988), with neglected and rejected adolescents reporting more overall social anxiety than average, popular, or controversial adolescents. More specifically, there was no significant difference between neglected and rejected adolescents in the area of social avoidance but rejected adolescents received higher scores on the FNE subscale of the SASC-R.

Crick and Ladd (1993) found different results from the previously mentioned studies, utilizing a different assessment measure of social anxiety. In their study, 338 third and fifth graders were evaluated on attribution style, social status, and social anxiety. The Franke and Hymel Social Anxiety and Social Avoidance Scale (Franke \& Hymel, 1984) and an attribution scale developed for the study were used and compared to children's sociometric nominations of the three peers they liked to play with the most and the three they liked to play with the least. In 
contrast to La Greca, et al (1988) and Inderbitzen et al. (1997), Crick and Ladd (1993) showed that neglected children were significantly less anxious than their average and rejected peers and did not differ from popular and controversial children. Furthermore, rejected children reported experiencing higher levels of social distress and loneliness than other sociometric status groups. It is important to note that the social anxiety scale used in this study is an unpublished measure for which there has been limited psychometric support.

\section{Discrepancies Between Prior Studies}

The discrepancies between study results may be due to differences in sociometric classification measures. La Greca et al., (1988) and La Greca and Stone (1993) used both positive peer nominations (i.e., the three children the respondent liked to play with the most) and a play preference rating scale (i.e., how much the respondent liked playing with each classmate). Crick and Ladd (1993), on the other hand used both positive and negative nominations, in which the participants identified three children they liked to play with the least and three they liked to play with the most. Inderbitzen, et al. (1997) used a sociometric classification procedure different from any of the previously mentioned authors, in which the participants chose three classmates who best matched one or more of seven behavioral descriptors.

Furthermore, the measures of social anxiety varied across studies. Inderbitzen (1997), La Greca, et al. (1988), and La Greca and Stone (1993) used the SASC, SASC-A, or SASC-Revised (SASC-R). Crick and Ladd (1993), however, used an unpublished measure of social anxiety and social avoidance for which there was limited empirical support. The subjective nature of social anxiety necessitates the use of self-report measures, especially for individuals who do not necessarily exhibit more overt symptoms of the disorder (e.g., actively avoiding social situations; La Greca \& Stone, 1993). 
The early literature in the area of social anxiety was limited by a lack of instruments specifically designed to assess social anxiety in children (Beidel, Turner, \& Morris, 1995). Development of the Social Phobia and Anxiety Inventory for Children (SPAI-C; Beidel et al., 1995; 1998) and the SASC-R (La Greca et al., 1988), psychometrically sound self-report assessments of social anxiety in children, facilitated further research in this area (Morris \& Masia, 1998).

Social Anxiety Scale for Children - Revised (SASC-R)

The SASC was the first psychometrically supported self-report measure of social anxiety in children and was originally developed by La Greca et al (1988) and later revised by La Greca and Stone (1993). The SASC-R is based on the concept of distinguishing between subjective and overt behavioral consequences of anxiety (La Greca \& Stone, 1993). Factor analysis of the SASC revealed two factors: social anxiety and distress (SAD) and fear of negative evaluation (FNE; La Greca et al., 1988). Additional items were included in the SASC-R to target more specific aspects of social avoidance and distress associated with peers. Factor analysis of the SASC-R revealed three subscales: FNE, social avoidance and distress with unfamiliar peers and/or situations (SAD-New), and persistent discomfort and distress in social situations (SADGen; La Greca \& Stone, 1993). The SASC-R has been demonstrated to have test-retest reliability, concurrent validity (Masia \& Morris, 1998), and higher internal consistencies than the SASC (La Greca \& Stone, 1993). Higher scores on the SASC-R have been correlated with low self-worth and low levels of perceived social competence (La Greca \& Stone, 1993). Social Phobia and Anxiety Inventory for Children (SPAI-C)

The SPAI-C (Beidel et al., 1995; 1998) assesses cognitive, somatic, and overt behavioral symptoms of social anxiety in children, according to diagnostic criteria from the Diagnostic and 
Statistical Manual of Mental Disorders ( $4^{\text {th }}$ ed. [DSM-IV] American Psychiatric Association, 1994). The authors developed the SPAI-C for use as a research tool and screening device in clinical settings (Beidel et al., 1995; 1998). The SPAI-C has been demonstrated to have testretest reliability, concurrent, discriminative, external, construct validity, and sensitivity to treatment effects (Beidel et al., 1995; Beidel et al., 1996; Morris \& Masia, 1998; Beidel, Turner, \& Morris, 2000). Beidel et al. (1995) reported a three-factor structure of the SPAI-C including Assertiveness/General Conversation (e.g., standing up for oneself in a social situation), Traditional Social Encounters (e.g., avoidance of situations where other children are present), and Public Performance (i.e., one’s discomfort towards performing in front of others). In a later study, Beidel et al (1996) reported a similar factor structure with five factors, including Assertiveness, General Conversation, Physical and Cognitive Symptoms, Avoidance, and Public Performance.

Comparison of the SPAI-C and SASC-R

The SPAI-C and SASC-R share some similarities and differences. While the SPAI-C is based on diagnostic criteria from the DSM-IV and is a specific measure of social phobia, the SASC-R measures a more general construct of social anxiety (Beidel et al., 1995). The SASC-R and SPAI-C both assess subjective feelings of anxiety and overt behavioral avoidance, as well as anxiety experienced with familiar and unfamiliar peers (Epkins, 2002). The SPAI-C more comprehensive than the SASC-R, assessing cognitive and somatic anxiety, and allowing for comparison of anxiety experienced across situations with unfamiliar peers, familiar peers, and adults (Epkins, 2002; Morris \& Masia, 1998).

Morris and Masia (1998) found a moderate correlation $(r=.63)$ and classification correspondence (63\%) between the two measures by examining upper and lower quartile scores 
(SPAI-C upper quartile scores $>20$, lower quartile scores $<$ 8; SASC-R upper quartile scores $>52$, lower quartile scores < 33) in a community sample. Epkins (2002) demonstrated a moderate to good correlation ( $r=.61$ to .77 ) and a classification correspondence ranging from $82 \%$ to 91\%, using community and clinic samples, and recommended cutoff scores for the SPAI-C and SASC-R. Both studies reported a large proportion of children who exceeded the cutoff scores on the SPAI-C and SASC-R from the community and clinical samples.

\section{Study Rationale}

Although previous research has demonstrated an overall association between social anxiety and peer nominated sociometric status, the results have varied somewhat based on the methods employed. Specific aspects and symptoms of social anxiety have not been examined in association with sociometric status. Associations among peer sociometric status and social anxiety primarily have been examined with respect to total and subscale scores on measures of social anxiety. Specific item, subscale, and factor scores may provide the ability to identify behavioral indicators of social anxiety which correlate with sociometric status.

Previous literature has demonstrated that socially anxious children are likely to be involved in poor peer relationships which may lead to the development of school, social, and mental health problems (Berndt, 2002; Woodward \& Fergusson, 1999; Ladd \& Troop-Gordon, 2003; Harrist et al., 1997). The elucidation of specific symptoms, items, and groups of items that correlate with particular sociometric categories may allow for a better understanding of the characteristics of social anxiety which are problematic in peer relationships. The association between specific items which assess anxiety and sociometric status may also help identify behavioral indicators of social anxiety within sociometric status groups. Sociometric nomination procedures can help generalize knowledge of the relation between social anxiety and sociometric 
status to children who are too young to complete a self-report assessment measure. Thus, clinicians and researchers might be able to provide prevention and intervention programs to young children who are at risk of developing social anxiety disorder, but cannot complete a selfreport assessment measure. Interventions may be better developed based on the knowledge of which anxious behaviors are indicative of children from a particular sociometric status group

The current study partially replicated and extended the previous literature on social anxiety and its association with social status. Thus, one of the purposes of this study was to clarify previous research and the association between social anxiety and sociometric status. In addition, it was anticipated that the current study would help identify particular aspects of social anxiety that correlate with sociometric status, allowing for the identification of children who are at particular risk of developing social anxiety disorder.

\section{SASC-R Hypotheses}

Consistent with the majority of previous literature (La Greca et al., 1988; Inderbitzen et al., 1997; Strauss et al., 1988), it was hypothesized that children sociometrically classified as neglected would endorse overall higher levels of social anxiety than the remaining sociometric status groups on the SASC-R. Rejected children often are described as aggressive, disruptive, and disliked by peers (Bierman \& Wargo, 1995). Consequently, rejected children’s attempts at socialization often are rebuffed by peers, resulting in increased sensitivity towards other's appraisal of them (La Greca et al., 1988). Therefore, rejected children also were expected to score higher on the SASC-R total score than their controversial, average, and popular peers yet lower than their neglected peers, similar to the findings of La Greca et al. (1988) and La Greca and Stone (1993). Anxiety-disordered children tend to be classified as neglected by their peers, and neglected children have been described as socially isolated (Strauss et al., 1988; Rosenblum 
\& Olson, 1997). Thus, it was predicted that neglected children would receive higher scores on the SASC-R than their peers with respect to social avoidance and distress in new situations (SAD-New; e.g., I feel shy around kids I don’t know) and Generalized Social Avoidance and Distress (SAD-Gen; e.g., I'm quiet when I'm with a group of kids).

Previous literature has demonstrated that rejected children fear situations in which they may be negatively evaluated by peers, similar to neglected children (La Greca et al., 1988). It was therefore predicted that neglected children would not obtain significantly different scores from rejected children on the Fear of Negative Evaluation (FNE) scale, however, both groups were expected to receive higher scores on this factor than children classified as average, popular, or controversial (La Greca et al., 1988; La Greca \& Stone, 1993). Rejected and neglected children also were expected to score higher than other social status groups but similarly to one another on item 20 (i.e., I feel nervous when I'm around certain kids). Item 20 loads on the SadNew factor, however, it is relevant to the anxiety that rejected children may experience in the presence of peers who have previously rebuffed their efforts at socialization, which is consistent with items on the FNE factor. Furthermore, literature suggests that rejected children experience high levels of anxiety with respect to being evaluated by peers, comparable to neglected children (La Greca et al., 1988; Inderbitzen et al., 1997; Buhs \& Ladd, 2000). Little research has been reported regarding characteristics of controversial children, largely due to the small proportions of children that make up this group (Hymel et al., 2002). Thus, the items on which controversial children scored highest were examined on an exploratory basis.

\section{SPAI-C Hypotheses}

In comparison to the SASC-R, less research has been conducted on the SPAI-C in relation to sociometric status. The SPAI-C is more comprehensive than the SASC-R and many of 
the items contain subcomponents (e.g., unfamiliar peers, familiar peers, and adults), which have not yet been examined with respect to sociometric status. Thus, many of the hypotheses for this measure were exploratory. Neglected children were expected to obtain higher SPAI-C total scores than their peers, consistent with the literature indicating that neglected children exhibit higher levels of social anxiety than other children (Rosenblum \& Olson, 1997; Strauss, Frame \& Forehand, 1987). Many of the characteristics of shy, withdrawn, and neglected children, including avoidance of social situations, overlap with the diagnostic criteria for social phobia (Beidel \& Turner, 1998), while rejected children’s maladaptive peer interactions have been linked to peer's descriptions of them as anxious and withdrawn (Strauss, Frame, \& Forehand, 1987). Research has demonstrated that neglected children score higher than their peers with respect to irrational fears of embarrassment and avoidance of social situations, while rejected children score lower on fear of embarrassment but also withdraw from and avoid social situations on measures of social anxiety (Hymel et al, 2002; Inderbitzen et al., 1997).

Thus, neglected children were expected to score higher than their peers on the SPAI-C in the areas of Assertiveness (e.g., too scared to ask questions in class), Performing in Public (e.g., scared when speaking in front of the class), and General Conversation (e.g., scared to meet new kids). Given that rejected children may fear the opinions and judgment of their peers in a similar manner as neglected children, both groups were expected to experience symptoms of anxiety with respect to social and evaluative situations. Furthermore, it was predicted that neglected and rejected children would score higher than other groups and not significantly different from each other in the areas of Cognitive and Physiological Symptoms (e.g., Before I go someplace I feel like I have to go to the bathroom) and Avoidance (e.g., I try to avoid social situations; Beidel et al., 1995; 1998). Item descriptors are presented for each SPAI-C factor scale in Table 1. 
There is little research available on the association between sociometric status and the Cognitive and Physiological Symptoms, and overt behavioral symptom items on the SPAI-C. Thus, cognitive, behavioral, and physiological symptoms were explored in association with sociometric status, with neglected children expected to report the highest level of all symptoms. Items 9-20 include subcomponents which ask the children to indicate their experience of anxiety within the context of familiar peers, unfamiliar peers, and adults. To meet the criteria for social anxiety disorder, according to the DSM-IV, a child must experience anxiety in the context of people other than adults (i.e., peers; APA, 2000). In particular, the experience of anxiety in the context of familiar people is not common for the general population but occurs in many socially anxious people (Stein, Walker, \& Forde, 1994). Little research has been conducted in the area of sociometric status as associated with reported anxiety across situations with familiar peers, unfamiliar peers, and adults. Sociometric status as associated with the social context (e.g., familiar peers) of reported anxiety was also explored.

\section{Method}

\section{Participants}

The data used in this study were previously collected as part of another investigation (Morris \& Masia, 1998). Participants were 268 children (142 girls, 126 boys) who provided parental consent and assent, out of a total of 502 children enrolled in the fourth through sixth grades of an elementary school in Morgantown, West Virginia. There were six classrooms at each grade level, with 26 to 29 children enrolled in each class. The overall consent rate for the sample was 53\%. Participants were 92 fourth graders (49 girls, 43 boys), 90 fifth graders (50 girls, 40 boys), and 86 sixth graders (43 girls, 43 boys). The children ranged in age from 9 to 12 years, with a mean of 10 years. The ethnic composition of the sample was $88 \%$ European 
American, 6\% African American, 4\% Asian, and 2\% were of mixed or other races. The majority of the participants were from middle class socioeconomic backgrounds, with about $25 \%$ in the lower-middle class income range, and $15 \%$ in the upper-middle class range.

\section{Measures}

SASC-R. The SASC-R is a 22-item measure designed to assess children's feelings of social anxiety in association with peers (La Greca, et al., 1988; La Greca \& Stone, 1993). The SASC-R is rated on a 5-point scale and is used with children aged 8 to 12 years. The SASC-R includes four filler items (e.g., I like to do things by myself) and three subscales: Fear of Negative Evaluation (FNE), Social Avoidance and Distress with respect to unfamiliar peers and/or new situations (SAD-New), and General Social Avoidance and Distress (SAD-Gen). The maximum score on the SASC-R is 90 and it has the ability to discriminate between highly socially anxious boys (i.e., score $\geq 50$ ), highly socially anxious girls (i.e., score $\geq 54$ ), and nonsocially anxious boys (i.e., score $\leq 36$ ) and girls (i.e., score $\leq 40$ ). The SASC-R has been demonstrated to have moderate test-retest reliability over a one-year interval and acceptable internal consistency (La Greca \& Stone, 1993).

SPAI-C. The SPAI-C is a 26-item, multidimensional measure of children's abnormal fears in various social situations (Beidel et al., 1995; 1998). Items are rated on a 0 (never) to 2 (most of the time or always) scale and 12 of the 26 items measure feelings of anxiety experienced during encounters with familiar peers, unfamiliar peers, and adults. The maximum possible score on the SPAI-C is 52 and a score of 18 is recommended to differentiate socially anxious children from non-socially anxious children (Beidel et al., 1995). The SPAI-C was written at a third-grade reading level and is recommended for use with children aged 8 to 14 years of age. The SPAI-C has been demonstrated to have high test-retest reliability over 2-week 
and 10-month time periods, and excellent internal consistency (Beidel et al., 1995; Beidel et al., 1996). The SPAI-C has the ability to successfully discriminate between typical children, children with social phobia, and children with other anxiety disorders, and has moderate concurrent validity with other measures of anxiety (Beidel et al., 1996; Morris \& Masia, 1998).

Sociometrics. Sociometric nominations are used to determine the extent to which children are liked and disliked by their peers. Please see procedure section below for a detailed description of the sociometric procedure used in this study. Morris (2001) demonstrated good stability over four years, using the same sociometric procedure and sample as the current study. Procedure

Children in the fourth through sixth grades were given consent forms during homeroom class to have their parents sign. All of those who received parental consent gave their assent to participate in the study. Participants completed the SPAI-C and SASC-R at one time, in a vacant classroom or the school cafeteria, and in groups of 25 or less. The order of measure administration was counterbalanced across classrooms and within each grade and no order effects were obtained. The children were given practice items prior to administration of the measures to make certain they understood how to complete the assessments. Verbal instructions were given and assistance was provided as needed by the participants.

Sociometric nominations were conducted by gender within each classroom. Each child was taken outside of his or her classroom individually and asked to name three children they liked to play with the most (i.e., positive nominations) and three they liked to play with the least (i.e., negative nomination). Nominations were summed and divided by the number of samegender nominators to obtain proportions of negative nominations and positive nominations received for each child. The statistical procedure outlined by French and Waas (1985) was used 
to classify children into sociometric status categories. A high proportion was defined as .5 standard deviation above the mean, while a low proportion was defined as .5 standard deviation below the mean. Thus, children were identified as popular if they received a high proportion of positive nominations and a low proportion of negative nominations, and rejected if they received a high proportion of negative nominations and a low proportion of positive nominations.

Neglected children were defined by a low proportion of both positive and negative nominations, while controversial children received a high proportion of both positive and negative nominations. Children were classified as average if they did not meet the criteria for any of the previously mentioned categories.

To illustrate how the procedure worked, "Fred" received 15 positive and 2 negative nominations from the 17 boys out of the 25 children in his classroom who participated in the sociometric nomination procedure. The positive nominations are summed equaling 15 and then divided by 17 resulting in a proportion of .88 positive nominations. Likewise, he would receive a negative proportion score of .12 (2/17). If the mean rating for positive nominations was .24 (SD $=.18)$ and the mean rating for negative nominations was $.22(S D=.16)$ then Fred would be assigned to the Popular sociometric status group, as he had received a high proposition of liked most and a low proportion of liked least nominations.

\section{Results}

Sociometric Status The percentage of children whose proportion scores met criteria for each of the five sociometric groups was as follows: $13.4 \%$ neglected, $14.6 \%$ rejected, $16.8 \%$ popular, $50.7 \%$ average, and $4.5 \%$ controversial. The percentage of participants who met criteria for each sociometric status group is consistent with previous studies (Morris et al., 1995; Terry \& Coie, 1991; Newcomb \& Bukowski, 1983). 
SASC-R. A one-way ANOVA was conducted to compare the five sociometric status groups (i.e., popular, rejected, neglected, controversial, and average) on total SASC-R scores and significant group differences were found, $F(4,263)=3.63, p<.05$. A one-way multivariate analysis of variance (MANOVA) was used to compare boys and girls, and sociometric status groups to one another on total scores, subscale scores (i.e., SAD-New, SAD-Gen, and FNE), and item 20 (i.e., I feel nervous when I'm around certain kids). There were no significant interactions between gender and sociometric status. Significant differences between genders were found for total SASC-R scores, the FNE, SAD-New, SAD-Gen subscales, and item 20 (i.e., I feel nervous when I'm around certain kids). Subsequently four univariate ANOVAs were conducted on the dependent variables. Pairwise comparisons were used to test the main effects and revealed that girls scored higher than boys. These data are presented in Table 2. Significant differences between sociometric status groups also were found for total SASC-R scores, the FNE and SADGen subscales, and no significant differences were found for item 20 (i.e., I feel nervous when I'm around certain kids ) and SAD-New. These data are presented in Table 3.

A Student-Neuman-Keuls multiple range post-hoc analysis was chosen to further examine significant differences between each sociometric status group on the SASC-R, based on its’ use in previous studies (Inderbitzen et al., 1997; Franz \& Gross, 2001). The Student Neuman-Keuls multiple range post hoc analysis calculates pairwise comparisons and can be used with groups of unequal sample sizes. Neglected children scored significantly higher on the total SASC-R than their popular and controversial peers $(p<.05)$ and not significantly different from rejected or average status children. No significant differences were found between rejected and other children on total SASC-R scores. On the FNE subscale, neglected and average children scored significantly higher than their controversial peers $(p<.05)$, but did not significantly differ 
from each other. Neglected children scored higher than popular children $(p<.05)$ on the SADGen subscale, and not significantly different from controversial, average, or rejected children. SASC-R item scores for controversial children were examined in comparison to their peer's scores. Controversial children did not score significantly higher than other children on any items as predicted, however, they did score significantly lower than all other sociometric status groups on item 3 (i.e., I worry about being teased; $p<.05$ ). Controversial children also scored lower than neglected children on item 9 (i.e., I'm afraid that others will not like me) and item 12 (i.e., I worry about what others say about me; $p<.05$ ). Furthermore, controversial children scored significantly lower than their average, rejected, and neglected peers on item 17 (i.e., I feel that other kids make fun of me; $p<.05$ ) and no different from their popular peers.

Total scores on the SASC-R were divided into quartiles. Children who obtained scores in the lowest quartile (score $<34 ; n=66$ ) were assigned to group1, and those who obtained scores in the highest quartile (score $>53 ; n=70$ ) were assigned to group 2 . A univariate ANOVA was performed to examine the differences between gender and sociometric status on SASC-R quartile scores. There was a significant effect of gender on quartile scores, $F(1,134)=17.282, p<.05$ with females having higher quartile scores than males (females $M=1.67$; males $M=1.33$ ). Significant differences between sociometric status groups on quartile scores were also obtained, $F(4,131)=3.000, \mathrm{p}<.05$. A Student-Neuman-Keuls multiple range post-hoc analysis was subsequently conducted, showing that neglected children had significantly higher quartile scores than controversial children $(p<.05)$ and were not significantly different from their rejected, popular, or average peers.

SPAI-C. A one-way ANOVA revealed significant group differences for sociometric status on total SPAI-C scores, $F(4,263)=4.06, p<.05$. A one-way MANOVA was used to 
compare gender and sociometric status groups on total scores, factors scores (i.e., Assertiveness, General Conversation, Physical and Cognitive Symptoms, Avoidance, and Public Performance), and context scores (i.e., familiar peers, unfamiliar peers, and adults). There were no significant interactions between gender and sociometric status on any of the dependent variables (e.g., factor scores). Significant differences between genders were obtained for total SPAI-C scores, all factor scores, and all context scores (i.e., familiar peers, unfamiliar peers, and adults). Univariate analysis on each dependent variable and further pairwise comparisons used to test these main effects showed that girls scored higher than boys. These data are presented in Table 4 . Significant differences between sociometric status groups were obtained for total SPAI-C scores, Cognitive and Physiological Symptoms, Avoidance, Public Performance factor scores, and in the context of familiar peers. No significant differences between sociometric status groups were found for Assertiveness or General Conversation factor scores, or in the context of unfamiliar peers or adults. These data are presented in Table 5.

A Student-Neuman-Keuls multiple range post-hoc analysis was subsequently conducted to further examine significant differences between each sociometric status group on the SPAI-C. As expected, neglected and rejected children scored significantly higher than their popular peers $(p<.05)$ on total SPAI-C scores, but did not differ from each other or their controversial and average peers. On the Cognitive and Physiological Symptoms and Avoidance factors, neglected, rejected, and average children scored significantly higher than their popular peers $(p<.05)$, yet not significantly different from each other and controversial children. Neglected children obtained significantly higher scores than controversial, average, and popular children $(p<.05)$ on the Public Performance factor, and did not differ from rejected children. With respect to familiar peers, neglected children scored significantly higher than popular children $(p<.05)$, yet 
not significantly different from controversial, rejected, and average children. SPAI-C item scores for controversial children were examined in comparison to their peers' scores. On item 24 (i.e., When I am with other people I think scary thoughts), controversial children obtained significantly lower scores than neglected children yet did not differ from other sociometric status groups.

Total scores on the SPAI-C were divided into quartiles. Children who obtained scores in the lowest quartile (score $<8 ; n=68$ ) were assigned to group 1 , and those who obtained scores in the highest quartile (score $>20 ; n=69$ ) were assigned to group 2. A univariate ANOVA was used to examine the differences between genders and sociometric status on SPAI-C quartile scores. Significant differences between gender on quartile scores were obtained, $F(1,135)=$ 22.04, $p<.05$, with females scoring higher than males (females, $M=1.67$; males, $M=1.29$ ). Significant differences were also found between sociometric status groups on quartile scores, $F$ $(4,132)=3.37, p<.05$. A Student-Neuman-Keuls multiple range post-hoc analysis was subsequently conducted, showing that neglected and rejected children obtained significantly higher quartile scores than their popular peers $(p<.05)$, and did not differ from other children.

\section{Discussion}

This investigation into specific aspects of social anxiety associated with peer nominated sociometric status partially replicated and extended previous research. In general, results were similar to those obtained by La Greca et al. (1988), La Greca and Stone (1993), and Inderbitzen, et al. (1997), with neglected children reporting the highest levels of social anxiety on both the SASC-R and SPAI-C. This was one of the first investigations to demonstrate that social anxiety and sociometric status are related to Cognitive and Physiological Symptoms, Avoidance, and Public Performance items on the SPAI-C. See Table 6 for a summary of findings. 


\section{SASC-R}

The majority of findings were consistent with hypothesis and consistent with previous findings (La Greca et al., 1988; La Greca et al., 1993; Inderbitzen et al., 1997). Inconsistent with hypothesis, rejected children did not obtain significantly higher SASC-R total scores than controversial, average, and popular children. This may reflect different experiences of anxiety between neglected and rejected children. Neglected and rejected children did, however, obtain significantly higher quartile scores on the SASC-R than their popular peers. This study produced unique results regarding average status children's reports of social avoidance as not significantly different from their neglected and rejected peers. Average children scored similarly to neglected and rejected children on the SAD-Gen subscale of the SASC-R.

SPAI-C

On the SPAI-C, no significant difference was found between sociometric status groups on the Assertiveness (e.g., I am too scared to ask questions in class) or General Conversation (e.g., I feel scared when I meet new kids) factors. This is one of the first investigations to demonstrate a significant association between sociometric status and Cognitive and Physiological Symptoms on the SPAI-C, with neglected children scoring the highest. Popular children scored significantly lower on Cognitive and Physiological Symptoms than children in the other sociometric status groups. This is consistent with literature which has shown socially anxious children to experience racing heart rates, sweaty hands, blushing, and body heat in social situations at higher degrees than non-anxious individuals (Edelmann \& Baker, 2002; Gerlach, Wilhelm, Gruber, \& Roth, 2001).

Neglected, rejected, and average children also endorsed higher levels of avoidance than their popular peers on the SPAI-C. This is consistent with these children's reports of generalized 
social avoidance and distress (i.e., SAD-Gen subscale) on the SASC-R. Previous literature has also shown neglected and rejected children to experience more distress than other children in social situations (La Greca \& Stone). This study produced unique results regarding average status children's reports of social avoidance as not significantly different from their neglected and rejected peers.

Neglected and rejected children scored higher than controversial, average, and popular status children on the Public Performance factor of the SPAI-C. These findings are consistent with previous literature which has indicated that neglected children have higher rates of social anxiety (La Greca et al., 1988; La Greca \& Stone, 1993) and one of the most common features of social anxiety is a fear of performing behaviors in public (Furmark et al, 1999). Contrary to hypothesis, there were no significant associations between sociometric status and Assertiveness and General Conversation factor scores. Cantrell and Prinz (1985) also showed no differences between sociometric status groups on measures of assertiveness and social skills. It is possible that neglected, controversial, average, popular, and rejected children have similar social skills, with neglected and rejected children avoiding social situations and withdrawing from other children as a result of anxiety rather than social skill deficits.

There were no differences between groups in the context of unfamiliar peers or adults. Neglected children, however, reported higher levels of anxiety in the context of familiar peers than did popular children. Most children experience some degree of anxiety in the presence of authority figures (e.g., teachers) and unfamiliar people. The DSM-IV criteria for social phobia require that a child experience anxiety in the presence of individuals other than adults. Socially anxious individuals commonly report experiencing high levels of anxiety in the context of familiar people (Stein, Walker, \& Forde, 1994). This is consistent with findings from the current 
study, in which neglected children endorsed higher rates of social anxiety on both the SPAI-C and SASC-R and reported experiencing more anxiety than other children in the context of familiar peers.

\section{Controversial Children}

The exploration of item score differences between controversial and other children on the SPAI-C and SASC-R yielded interesting results. Controversial children endorsed experiencing fewer fears of negative social evaluation than other children on the SASC-R and the SPAI-C. These findings are consistent with previous literature which has shown controversial children to be less socially distressed than their peers (Crick \& Ladd, 1993). Controversial children are highly liked by some peers and highly disfavored by others, but may not experience much distress about being disliked. Controversial children have been shown to use manipulative, aggressive behavior with peers to reach a goal. While some children dislike their controversial peers, it has been hypothesized that other children are charmed and provide social support, reinforcing aggressive behavior and reducing the likelihood of controversial children experiencing distress from being disliked (DeRosier \& Thomas, 2003). Controversial children were also shown to be more likely to fail at least one grade in school and have more involvement with the juvenile justice system than their average, neglected, and popular peers five years after the initial sociometric nomination procedure was conducted (Ollendick, Weist, Borden, \& Greene, 1992).

\section{Gender Differences}

Gender differences were found on the SPAI-C and SASC-R, with girls endorsing higher levels of anxiety than boys on subscale and factor scores on the SASC-R and SPAI-C. Furthermore, females were more likely to score in the highest quartile. This is consistent with 
literature indicating higher rates of reported social anxiety in females than males (La Greca, 1998; Beidel et al., 1998), which may be due to differences in socialization and/or genetics (Furmark et al., 1999).

\section{Summary}

The results of the current study replicated and extended previous literature. Consistent with previous literature, neglected children reported higher levels of social anxiety than other children on the SPAI-C and SASC-R. Furthermore, differences were found between sociometric status groups on subscale, item, context, and factor scores. The current investigation extended the literature on controversial children by demonstrating lower rates of anxiety for these children associated with being negatively evaluated by peers. This was one of the first investigations to examine the association between SPAI-C factor scores (i.e., Assertiveness, General Conversation, Cognitive and Physiological Symptoms, Avoidance, and Public Performance), the context of social anxiety (i.e., familiar peers, unfamiliar peers, and adults), and sociometric status. Compared to their peers, neglected children scored the highest on Cognitive and Physiological Symptoms, Avoidance, and Public Performance factors, and in the presence of familiar peers.

\section{Limitations and Future Directions}

Limitations of this study and directions for future research should be noted. Controversial children in the current investigation made up a very small portion of the sample, limiting the specific findings relevant to this group. Future research might benefit from focusing on larger samples of controversial children to develop a better understanding of this highly liked and highly disliked group. The current study also focused on self-reports of social anxiety and peerreports of sociometric status. Behavioral observations and teacher reports may provide 
information about social interactions within and between sociometric status groups to further validate findings. The sample in the current study primarily consisted of Caucasian children from middle-class socioeconomic backgrounds. Future research may benefit from a multicultural focus on children from different socioeconomic backgrounds to determine whether differences exist in sociometric status categories and levels of social anxiety. The use of same-gender nominations to determine sociometric status was not considered a limitation of the current study. Previous research has shown that children typically identify same-gender peers as their friends throughout childhood and early adolescence (see Maccoby, 1998, for a review). Positive interactions were found to be more common among children in same-gender dyads than those in mixed-gender dyads (Vaughn, Colvin, Azria, Caya, \& Krzysik, 2001).

Implications

In general, the current investigation has many implications for intervention and prevention of social anxiety and peer relationship problems. Results suggest that neglected and rejected children in particular should be targeted early to prevent the development of social anxiety. Results from the current study also indicate that this may be advantageous for average status children as well. Furthermore, children may benefit from psycho-education about physiological symptoms of anxiety (e.g., heart racing, blushing). Interventions, such as exposure to performance situations and the use of response-blocking for avoidance may assist in reducing fear in response to heightened arousal, thus reducing the likelihood that significant anxiety concerns will develop. 


\section{References}

American Psychiatric Association (1994). Diagnostic and Statistical Manual of Mental Disorders, $4^{\text {th }}$ edition. Washington, DC: American Psychiatric Association.

American Psychiatric Association (2000). Diagnostic and Statistical Manual of Mental Disorders, $4^{\text {th }}$ edition - Text Revision. Washington DC: American Psychiatric Association.

Beidel, D. C., \& Morris, T. L. (1995). Social phobia. In J. S. March (Ed.), Anxiety disorders in children and adolescents (pp. 181-211). New York: Guilford.

Beidel, D. C., \& Turner, S. M. (1998). Shy children, phobic adults: Nature and treatment of social phobia. Washington, DC : American Psychological Association.

Beidel, D. C., Turner, S. M., \& Fink, C. M. (1996). Assessment of childhood social phobia: Construct, convergent, and discriminative validity of the social phobia and anxiety inventory for children (SPAI-C). Psychological Assessment, 8, 235240.

Beidel, D. C., Turner, S. M., \& Morris, T. L. (1995). A new inventory to assess childhood social anxiety and phobia: The social phobia and anxiety inventory for children. Psychological Assessment, 7, 73-79.

Beidel, D. C., Turner, S. M., \& Morris, T. L. (2000). Behavioral treatment of childhood social phobia. Journal of Consulting and Clinical Psychology, 68, 1072-1080.

Beidel, D. C., Turner, S. M., \& Morris, T. L. (1998). Manual for the Social Phobia and Anxiety Inventory for Children (SPAI-C). New York: Toronto.

Bell-Dolan, D. J., Foster, S. L., \& Christopher, J. S. (1995). Girl’s peer relations and internalizing problems: Are socially neglected, rejected, and withdrawn girls at risk? 
Journal of Clinical Child Psychology, 24, 463-473.

Berndt, T. J. (2002). Friendship quality and social development. Current Directions in Psychological Science, 11, 7-10.

Bierman, K. L. \& Wargo, J. B. (1995). Predicting the longitudinal course associated with aggressive-rejected, aggressive (nonrejected), and rejected (nonaggressive) status. Development and Psychopathology, 7, 669-682.

Buhs, E. S., \& Ladd, G. W. (2001). Peer rejection as an antecedent of young children's school adjustment: An examination of mediating processes. Developmental Psychology, 37, 550560.

Cantrell, V. L., \& Prinz, R. J. (1985). Multiple perspectives of rejected, neglected, and accepted children: Relation between sociometric status and behavioral characteristics. Journal of Consulting and Clinical Psychology, 53, 884-889.

Coie, J. D., Dodge, K. A., Coppotelli, H. (1982). Dimensions and types of social status: A crossage perspective. Developmental Psychology, 18, 557-570.

Crick, N. R., \& Ladd, G. W. (1989). Nomination attrition: Does it affect the accuracy of children’s sociometric classifications? Merrill-Palmer Quarterly, 35, 197-207.

Crick, N. R., \& Ladd, G. W. (1993). Children’s perceptions of their peer experiences: Attributions, loneliness, social anxiety, and social avoidance. Developmental Psychology, 29, 244-254.

DeRosier, M. E., \& Thomas, J. M. (2003). Strengthening sociometric prediction: Scientific advances in the assessment of children's peer relations. Child Development, 75, 13791392.

Edelmann, R. J., \& Baker, S. R. (2002). Self-reported and actual physiological symptoms in 
social phobia. British Journal of Clinical Psychology, 41, 1-14.

Epkins, C. C. (2002). A comparison of two self-report measures of children's social anxiety in clinic and community samples. Journal of Clinical Child and Adolescent Psychology, 31, 69-79..

Frame, C. L., \& Strauss, C. C. (1987). Parental informed consent and sample bias in gradeschool children. Journal of Social and Clinical Psychology, 5, 227-236.

Frank, S., \& Hymel, S. (1984). Franke. Social anxiety in children: The development of selfreport measures. Paper presented at the third biennial meeting of the University of Waterloo Conference on Child Development, Waterloo, Ontario, Canada.

French, D. C., \& Waas, G. A. (1985). Behavior problems of peer-neglected and peerrejected elementary-age children: Parent and teacher perspectives. Child Development, 56, 246-252.

Furmark, T. (2002). Social phobia: overview of community surveys. Acta Psychiatrica Scandinavica, 105, 84-93.

Furmark, T., Tillfors, M., Everz, P. O., Marteinsdottir, I., Gefvert, O., \& Fredrickson, M. (1999). Social phobia in the general population: Prevalence and Sociodemographic Profile. Social Psychiatry and Psychiatric Epidemiology, 34, 416-424.

Gerlach, A. L., Wilhem, F. H., Gruber, K., \& Roth, W. (2001). Blushing and physiological arousability in social phobia. Journal of Abnormal Psychology, 110, 247-258.

Ginsburg, G. S., La Greca, A. M., \& Silverman, W. K. (1998). Social anxiety in children with anxiety disorders: Relation with social and emotional functioning. Journal of Abnormal Child Psychology, 26, 175-185.

Harrist, A. W., Zaia, A. F., Bates, J. E., Dodge, K. A., \& Petit, G. S. (1997). Subtypes of 
social withdrawal in early childhood: Sociometric status and social-cognitive differences across four years. Child Development, 68, 278-294.

Hymel, S., Vaillancourt, T., McDougall, P., \& Renshaw, P. D. (2002). Peer acceptance and rejection in childhood. In P. K. Smith \& C. H. Hart (Eds.), Blackwell handbook of childhood social development (pp. 265-284). Massachusetts: Blackwell Publishers.

Inderbitzen, H. M., Walters, K. S., \& Bukowski, A. L. (1997). The role of social anxiety in adolescent peer relations: Differences among sociometric status groups and rejected subgroups Journal of Clinical Child Psychology, 26, 338-348.

Kashdan, T. B. \& Herbert, J. D. (2001). Social anxiety disorder in childhood and adolescence: Current status and future directions. Clinical Child and Family Psychology Review, 4, 3761.

Kessler, R. C., McGonagle, K. A., Zhao, S., Nelson, C. B., Hughes, M., Eshelman, S., Wittchen, H., \& Kendler, K. S. (1994). Lifetime and 12-month prevalence of DSM-III-R psychiatric disorders in the United States. Archives of General Psychiatr, 51, 8-19.

La Greca, A. M., Dandes, S. K., Wick, P., Shaw, K., \& Stone, W. L. (1988). Development of the social anxiety scale for children: Reliability and concurrent validity. Journal of Clinical Child Psychology, 17, 84-91.

La Greca, A. M., \& Lopez, N. (1998). Social anxiety among adolescents: Linkages with peer relations and friendships. Journal of Clinical Child Psychology, 26, 83-94.

La Greca, A. M., \& Stone, W. L. (1993). Social anxiety scale for children-revised: Factor structure and concurrent validity. Journal of Clinical Child Psychology, 22, 1727. 
Ladd, G. W. (1999). Peer relationships and social competence during early and middle childhood. Annual Review of Psychology, 50, 333-359.

Ladd, G. W., Buhs, E. S., \& Troop, W. (2002). Children’s interpersonal skills and relationships in school settings: Adaptive significance and implications for school-based prevention and intervention programs. In P. K. Smith \& C. H. Hart (Eds.), Blackwell handbook of childhood social development (pp. 394-415). Massachusetts: Blackwell Publishers.

Ladd, G. W., \& Troop-Gordon, W. (2003). The role of chronic peer difficulties in the development of children’s psychological adjustment problems. Child Development, 74, 1344-1367.

Maccoby, E. E. (1998). The two sexes: Growing up apart, coming together (pp. 15-58). Massachusetts: Belknap Press/Harvard University Press.

Morris, T. L. (2001). Social phobia. In M. W. Vasey \& M. R. Dadds (Eds.), Developmental psychopathology of anxiety (pp. 435-458). London: Oxford University Press.

Morris, T. L., \& Masia, C. L. (1998). Psychometric evaluation of the social phobia and anxiety inventory for children: Concurrent validity and normative data. Journal of Clinical Child Psychology, 27, 452-458.

Morris, T. M., Messer, S. C., \& Gross, A. M. (1995). Enhancement of the social interaction and status of neglected children: A peer-pairing approach. Journal of Clinical Child Psychology, 24, 11-20.

Musun-Miller, L. (1990). Sociometric with preschool children: Agreement between different strategies. Journal of Applied Developmental Psychology, 11, 195-207.

Newcomb, A. F., \& Bukowski, W. M. (1983). Social impact and social preference as 
determinants of children's peer group status. Developmental Psychology, 19, 856-867.

Newcomb, A. F., Bukowski, W. M., \& Pattee, L. (1993). Children’s peer relations: A metaanalytic review of popular, rejected, neglected, controversial, and average sociometric status. Psychological Bulletin, 113, 99-128.

Ollendick, T. H., Weist, M. D., Borden, C. M., \& Greene, R. W. (1992). Sociometric status and academic, behavioral, and psychological adjustment: A five-year longitudinal study. Journal of Consulting and Clinical Psychology, 60, 80-87.

Otto, M. W., Pollack, M. H., Maki, K. M., Gould, R. A., Worthington, J. J., Smoller, J. W., \& Rosenbaum, J. F. (2001). Childhood history of anxiety disorders among adults with social phobia: Rates, correlates, and comparisons with patients with panic disorder. Depression and Anxiety, 14, 209-213.

Prout, H. T., \& Chizik, R. (1988). Readability of child and adolescent self-report measures. Journal of Consulting and Clinical Psychology, 56, 152-154.

Reynolds, C. R., \& Richmond, B. O. (1978). What I think and feel: A revised measure of children’s manifest anxiety. Journal of Abnormal Child Psychology, 6, 271-280.

Rosenblum, K. L., \& Olson, S. L. (1997). Assessment of peer neglect in the preschool years: A short-term longitudinal study. Journal of Clinical Child Psychology, 26, 424-432.

Stein, M. B., Walker, J. R., \& Forde, D. R. (1994). Setting diagnostic thresholds for social phobia: considerations from a community survey of social anxiety. American Journal of Psychiatry, 151, 408-412.

Strauss, C. C., Frame, C. L., \& Forehand, R. (1987). Psychosocial impairment associated with anxiety in children. Journal of Clinical Child Psychology, 16, 235-239. 
Strauss, C. C., Lahey, B. B., Frick, P., Frame, C. L., \& Hynd, G. W. (1988). Peer social status of children with anxiety disorders. Journal of Consulting and Clinical Psychology, 56, 137141.

Terry, R., \& Coie, J. D. (1991). A comparison of methods for defining sociometric status among children. Developmental Psychology, 27, 867-880.

Vaughn, B. E., Colvin, T. N., Azria, M. R., Caya, L., \& Krzysik, L. (2001). Dyadic Analyses of Friendship in a Sample of Preschool-Age Children Attending Head Start: Correspondence between Measures and Implications for Social Competence. Child Development, 72, 862-878.

Woodward, L. J. \& Fergusson, D. M. (1999). Childhood peer relationship problems and psychosocial adjustment in late adolescence. Journal of Abnormal Child Psychology, 27, 87-104. 
Table 1.

SPAI-C Factor Scales and Item Descriptions

Factor

Item Number

Item Description

Assertiveness

8. $\quad$ too scared to ask any questions in class

10. feel scared and do not know what to do if someone starts arguing

11. feel scared and don't know what to say if asked to something I don't want to do

12. feel scared and don’t know what to do when in an embarrassing situation

13. feel scared saying what I think if somebody says that something is wrong or bad

17. feel scared in front of others when in a school play, choir, music, or dance

18. feel scared when made fun of or ignored by others

\section{General Conversation}

1. feel scared in a social situation with more than 6 boys and girls

3. feel scared when I have to do something while others watch

7. feel scared when meeting new kids

14. feel scared when I start to talk to others

15. feel scared if I have to talk with others for longer than a few minutes

16. feel scared when speaking in front of others 
Table 1. (continued)

Factor

Item Number

Item Description

Physical and Cognitive Symptoms

21. think about what might go wrong before going someplace with others

24. think scary thoughts when I am with others

25. feel (somatic symptoms) before going someplace

26. feel (somatic symptoms) when I am in a social setting

Avoidance

2. feel scared when I becom24e the center of attention

6. feel scared and go home early from social events

19. try to avoid social situations

20. leave social situations

Public Performance

3. feel scared when I have to do something while others watch

4. feel scared when I have to speak or read in front of a group

5. feel scared when answering questions in front of others

16. feel scared when speaking in front of others 
Table 2.

Pairwise Comparisons by Gender for the SASC-R

\begin{tabular}{lccccc}
\hline \multicolumn{2}{c}{ Males } & \multicolumn{2}{c}{ Females } & \\
SASC- $R$ & $M$ & SE & $M$ & SE & Mean Difference \\
& & & & & \\
SASC-R Total & 39.76 & 1.20 & 48.04 & 1.13 & $8.28^{* *}$ \\
FNE & 20.15 & .55 & 23.77 & .52 & $3.61^{* *}$ \\
SAD-New & 14.46 & .42 & 16.70 & .39 & $2.24^{* *}$ \\
SAD-Gen & 7.64 & .30 & 9.20 & .28 & $1.56^{* *}$ \\
SASC-20 & 2.38 & .10 & 2.78 & .14 & .39 \\
\end{tabular}

${ }^{*} p<.05 .{ }^{*} * p<.001$ 
Table 3.

Mean SASC-R Scores by Sociometric Status Groups

\begin{tabular}{lcccccc}
\hline & \multicolumn{5}{c}{ Sociometric Status Group } & \\
\cline { 2 - 5 } SASC & Neglected & Rejected & Popular & Average & Controversial & F (4, 263) \\
& & & & & \\
SASC-R Total & 49.22 & 44.44 & 40.02 & 44.91 & 34.92 & $3.63^{*}$ \\
FNE & 23.89 & 21.72 & 21.23 & 224.1 & 16.92 & $2.95^{*}$ \\
SAD-New & 16.50 & 15.51 & 14.02 & 16.10 & 14.50 & 2.06 \\
SAD-Gen & 9.78 & 8.44 & 7.48 & 8.63 & 6.67 & $3.22^{*}$ \\
SASC-20 & 2.92 & 2.51 & 2.40 & 2.65 & 2.08 & 1.25 \\
& & & & & & \\
\hline
\end{tabular}

${ }^{*} p<.05$. 
Table 4.

Pairwise Comparisons by Gender for the SPAI-C

\begin{tabular}{|c|c|c|c|c|c|}
\hline \multirow[b]{2}{*}{ SPAI-C } & \multicolumn{2}{|c|}{ Males } & \multicolumn{2}{|c|}{$\underline{\text { Females }}$} & \\
\hline & $M$ & $S E$ & $M$ & $S E$ & Mean Difference \\
\hline
\end{tabular}

SPAI-C Total

$\begin{array}{lllll}11.47 & .74 & 16.69 & .70 & 5.21^{* *}\end{array}$

Assertiveness

$\begin{array}{lllll}3.77 & .23 & 5.52 & .22 & 1.75^{* *}\end{array}$

General Conversation

$\begin{array}{lllll}2.54 & .19 & 3.61 & .18 & 1.07^{* *}\end{array}$

Cognitive and Physiological Symptoms

$\begin{array}{llllll}1.54 & .14 & 2.44 & .13 & .89 * *\end{array}$

Avoidance

$\begin{array}{lllll}1.57 & .13 & 2.26 & .12 & .69 * *\end{array}$

Public Performance

$\begin{array}{lllll}1.87 & .16 & 2.72 & .15 & .84 * *\end{array}$

Familiar Peers
3.62
.35
5.27
.33
$1.64 *$

Unfamiliar Peers
6.93
.50
10.67
.48
$3.74 * *$ 
Table 4. (continued)

\begin{tabular}{|c|c|c|c|c|c|}
\hline \multirow[b]{2}{*}{$S P A I-C$} & \multicolumn{2}{|c|}{$\underline{\text { Males }}$} & \multicolumn{2}{|c|}{$\underline{\text { Females }}$} & \multirow[b]{2}{*}{ Mean Difference } \\
\hline & $M$ & $S E$ & $M$ & $S E$ & \\
\hline \multicolumn{6}{|l|}{ Adults } \\
\hline & 7.50 & .48 & 9.35 & .45 & $1.85 *$ \\
\hline
\end{tabular}

${ }^{*} p<.05 .{ }^{* *} p<.001$ 
Table 5.

Mean SPAI-C Scores by Sociometric Status Groups

Sociometric Status Group

SPAI-C Neglected Rejected Popular Average Controversial F $(4,263)$

SPAI-C Total

$\begin{array}{llllll}17.70 & 16.13 & 10.56 & 14.25 & 11.36 & 4.06 *\end{array}$

Assertiveness

$\begin{array}{llllll}5.33 & 4.96 & 3.95 & 4.81 & 3.44 & 1.61\end{array}$

General Conversation

$\begin{array}{llllll}3.81 & 3.52 & 2.60 & 3.06 & 2.60 & 1.60\end{array}$

Cognitive and Physiological Symptoms

$\begin{array}{llllll}2.62 & 2.32 & 1.30 & 2.07 & 1.38 & 3.98^{*}\end{array}$

Avoidance

$\begin{array}{llllll}2.45 & 2.45 & 1.21 & 1.92 & 1.77 & 4.43^{*}\end{array}$

Public Performance

$\begin{array}{lllll}3.29 & 2.67 & 1.79 & 2.21 & 1.63\end{array}$

Familiar Peers

$\begin{array}{llllll}5.66 & 4.76 & 3.00 & 4.56 & 5.00 & 2.42^{*}\end{array}$

Unfamiliar Peers
10.38
9.97
8.15
8.66
6.75
1.75 
Table 5. (continued)

Sociometric Status Group

SPAI-C Neglected Rejected Popular Average Controversial F $(4,263)$

Adults

9.72

9.23

6.86

8.61

6.91

1.69

$* p<.05$ 
Table 6.

Summary of Findings

$\underline{\text { Hypotheses }}$

\section{Findings}

\section{SASC-R Total Scores}

Neglected $>$ all other groups

Rejected > Controversial, Average, \& Popular

SASC-R Subscales

Neglected $>$ other groups on SAD-New

Neglected $>$ other groups on SAD-Gen

Other groups < Rejected \& Neglected on FNE

\section{Item 20}

Differences between groups

\section{Controversial Children}

Controversial > others on some items

\section{SASC-R Total Scores}

Neglected $>$ Controversial \& Popular $(p<.05)$

Rejected children not different from peers

\section{SASC-R Subscales}

No differences between groups

Neglected $>$ Popular $(p<.05)$

Controversial $<$ Neglected \& Average $(p<.05)$

\section{Item 20}

No significant differences between groups

\section{Controversial Children}

Not significantly higher on any items

Controversial $<$ others on $3(p<.05)$

Controversial $<$ Neglected on $9 \& 12(p<.05)$

Controversial < Average, Neglected \&

Rejected on $17(p<.05)$ 
Table 6. (continued)

Summary of Findings

Hypotheses

Findings

\section{SPAI-C Total Scores}

Neglected $>$ all other groups

Rejected $>$ Controversial, Average, \& Popular

SPAI-C Factors

Assertiveness \& General Conversation:

Neglected $>$ all other groups

Public Performance:

Neglected $>$ all other groups

Cognitive and Physiological Symptoms \&

Avoidance:

All other groups < Neglected \& Rejected

Familiar \& Unfamiliar Peers, \& Adults

Differences expected between groups
SPAI-C Total Scores

Popular $<$ Neglected \& Rejected $(p<.05)$

SPAI-C Factors

Assertiveness \& General Conversation:

No significant differences between groups

Public Performance

Neglected $>$ Controversial, Average, \&

Popular $(p<.05)$

Cognitive and Physiological Symptoms \&

Avoidance:

Popular < Neglected, Rejected, \& Average

$$
(p<.05)
$$

Familiar Peers

Neglected $>$ Popular $(p<.05)$ 
Table 6. (continued)

Summary of Findings

$\underline{\text { Hypotheses }} \quad$ Findings

Familiar \& Unfamiliar Peers, \& Adults

Differences expected between groups

\section{Controversial Children}

Controversial $>$ others on some items

\section{Unfamiliar Peers \& Adults}

No significant differences between groups

\section{Controversial Children}

Not significantly higher on any items

Controversial $<$ Neglected on $24(p<.05)$ 